\title{
Seabird life histories and climatic fluctuations: a phylogenetic-comparative time series analysis of North Atlantic seabirds
}

\author{
Hanno Sandvik and Kjell Einar Erikstad \\ H. Sandvik (hanno@evol.no), Dept of Biology, Univ. of Tromsø, NO-9037 Tromsø, Norway, and Norwegian Inst. for Nature Research, Polar \\ Environmental Centre, NO-9296 Tromsø, Norway (present address: Dept of Biology, Norwegian Univ. of Science and Technology, NO-7491 \\ Trondheim, Norway). - K. E. Erikstad, Norwegian Inst. for Nature Research, Polar Environmental Centre, NO-9296 Tromsø, Norway.
}

\begin{abstract}
In the light of the predicted changes in climate as a consequence of global warming, it is a major concern how animal species will respond to altered meteorological and oceanographic conditions. Seabirds constitute a diverse group of marine top predators which have relatively low fecundity and high annual survival rates. In order to predict effects of climate change, it is a necessary precondition to first understand responses to naturally occurring climatic fluctuations. While the ecological effects of different large-scale climatic phenomena have received much attention in the recent past, the factors determining the responses of seabirds are still little understood. We analyze more than a hundred previously published time series of seabird offspring production and adult survival rates in the North Atlantic in order to detect climatic signals in this data base. As our analyses are phylogenetic-comparative, we are able to search for patterns across species. Using the correlation of these parameters with the North Atlantic Oscillation (NAO) as a measure of responsiveness to climatic variability, we find that effects of climate on either parameters considered are not more common than expected by chance. The magnitudes of the responsivenesses were not entirely randomly distributed throughout the seabird phylogeny, but were not strongly related to the explanatory variables considered. However, some tendencies indicate that both life-history traits and feeding ecology may influence how seabirds respond to climatic variability. An explanation of those patterns based on life-history theory is given.
\end{abstract}

Global change is predicted to change both the mean and variance of many climatological and oceanographic parameters (Trenberth 2001b, Hunt and Elliott 2004) which are relevant to animal populations (Aebischer et al. 1990, Ainley and Divoky 2001, Walther et al. 2002). In several areas, the warming signal is already apparent, as shown by increases in water temperature in the Southern Ocean (Gille 2002) or the North Atlantic (Levitus et al. 2000). Climatic and oceanographic systems are highly complex, not to speak of their interaction with biota, both on the scale of particular species (Kitaysky and Golubova 2000) and of ecological communities (Hjermann et al. 2004). The understanding of the naturally occurring fluctuations and their influence on animal populations is a crucial step towards an understanding of how global change will affect different species. Of those naturally occurring large-scale patterns, the El Niño-Southern Oscillation (ENSO; Trenberth 2001a) and the North Atlantic Oscillation (NAO; Hurrell et al. 2001) may be the ones whose effects on biological systems are most intensely studied (reviewed by Stenseth et al. 2003, 2004).

Seabirds are a group of marine top-predators with an extremely "slow" life history, which is to say that they have comparatively high survival and low fecundity (Bennett and Owens 2002). This makes them especially vulnerable from environmental changes because even small decreases in survival will potentially have huge effects on the life time reproductive success of individuals (Wooller et al. 1992), and on the prospects of whole populations and, ultimately, species. Seabirds furthermore offer some unique opportunities for the analysis of causal links: they share a marine environment, while at the same time exhibiting an amazing variation in trophic relations, behavioural traits, life-history tactics and geographic distributions (Weimerskirch 2002).

So far, a few studies have documented effects of NAO, which is a widely used proxy for climatic conditions in and around the North Atlantic, on breeding phenology, demographic rates and population size of seabirds (reviewed by Reid et al. 1999, Thompson and Grosbois 2002, Durant et al. 2004b). In most cases studied so far, the effect of NAO on seabirds is indirect, i.e. it is the effect of temperature on prey abundance and availability that seems to be the major link between large-scale climate indices and demographic responses. However, attempts to focus simultaneously on more than one species are still sparse. If we are to predict which species are most likely to respond to 
climatic variation, and what those responses will look like, we will have to generalize findings across species. Searching for lawful generalizations across species is exactly what nomothetic science is about (Hull 1999), and in biology the phylogenetic-comparative method is the prime tool for revealing such interspecific patterns (Mayr 1988, ch. 1, Martins and Hansen 1996, Sandvik 2001, ch. 6). To a certain degree, this approach involves a trade-off between generality and precision. For example, by generalizing findings across species, we do not know how well the results fit every single of them. Therefore certainly both approaches are not only legitimate but also necessary for a full understanding of, among other things, the climate response of seabirds.

Our approach was to carry out exploratory analyses (sensu Anderson et al. 2001) using existing time series on seabird demographic parameters. Our main goal was to search for the existence of patterns - or lawfulness - across species. We did this in a two-step process. First, we investigated the prevalence and magnitude of responses to climatic variability, as measured by the NAO index, in two demographic parameters, offspring production and adult survival. In the second step, we analyzed whether the responsiveness to climate was related to biological characteristics of the species, considering ecology and lifehistory as explanatory variables. As ecological variables we considered two measures of feeding range, viz. foraging distance and diving depth, because these parameters can be considered as proxies for the vulnerability of seabirds (Furness and Ainley 1984, Furness and Barrett 1991, Furness and Tasker 2000). The demographic variables considered were adult survival, age at maturity, clutch size and chick production. It can be derived from life-history theory (Wooller et al. 1992) that species should be the more reluctant to invest into any specific breeding attempt at the cost of future ones, the lower their fecundity and the higher their adult survival are (Erikstad et al. 1998). This is because, in long-lived species, adult survival is the lifehistory trait which has the highest elasticity, i.e. which is under the strongest selection pressure (Gadgil and Bossert 1970, Stearns 1992). Our expectation is therefore that the responsiveness to climate should decrease with increasing longevity.

\section{Material and methods}

The time series used in our analyses were found in a literature search. All studies reporting chick production or adult survival of seabirds in the North Atlantic for at least four consecutive years were included. "Seabird" was defined as any species belonging to the Phalacrocoracidae (shags and cormorants), Sulidae (gannets and boobies), Procellariiformes (tubenoses), Alcidae (auks) or Lari (gulls and allies; the nomenclature follows Schreiber and Burger 2002b). Chick production was defined as the number of chicks fledged per breeding pair. The final data set contained 106 studies on 23 species, differing in length between 4 and $44 \mathrm{yr}$ (see Table 1 for details). Tests were also conducted on two modified data sets, one restricted to data from the main water body of the North Atlantic Ocean (i.e. excluding data from the Baltic Sea, Kattegatt, Skagerak, Lake IJssel and White Sea), and one additionally constrained to highquality data, i.e. to longer time series and to original studies that used more reliable sampling or estimation methods (Table 1). Results inferred from these modified data sets are not mentioned unless they differed from the standard data set. The studies used and species names are listed in Table S1 in the Appendix.

Responsiveness of chick production and adult survival to climatic variability was measured as the coefficient of determination, $\mathrm{r}^{2}$, obtained in Pearson's product-moment correlation analysis between the characters of interest and the extended winter NAO index. This index is the mean of the principal-component based NAO index values for the period December-March (Hurrell 1995), and was retrieved from Hurrell (2005). The reason to choose the extended winter index of NAO is that the signal:noise ratio of NAO is highest in winter (Barnston and Livezey 1987, Hurrell et al. 2003), and that many biological studies have found it to be the most ecologically relevant index (Ottersen et al. 2001).

Survival rates were logit-transformed before processing. In order to avoid spurious correlation, each climatic and demographic time series was individually pre-whitened prior to further analysis. "Pre-whitening" entailed substituting each time series with the residuals from its optimal autoregressive model, where the order of the autoregressive model required was inferred using Akaike's information

Table 1. Data sets used in the analyses and their characteristics.

\begin{tabular}{|c|c|c|c|c|c|c|}
\hline \multirow[t]{2}{*}{ Name } & \multicolumn{3}{|c|}{ Number } & \multicolumn{2}{|c|}{ Length } & \multirow[t]{2}{*}{ Comments } \\
\hline & time series & species & $\min$. & $\max$ & mean & \\
\hline Standard data set & & & & & & Entire North Atlantic, irrespective of data quality \\
\hline chick production & 72 & 22 & 4 & 30 & 10 & \\
\hline adult survival & 34 & 17 & 4 & 44 & 12 & \\
\hline Restricted data set & & & & & & $\begin{array}{l}\text { Excluding data from the Lake IJssel, Baltic Sea } \\
\text { and White Sea }\end{array}$ \\
\hline chick production & 68 & 21 & 4 & 30 & 10 & \\
\hline adult survival & 33 & 16 & 4 & 44 & 11 & \\
\hline High quality data set & & & & & & $\begin{array}{l}\text { As restricted data set, but time series length } \\
\text { at least eight years; furthermore: }\end{array}$ \\
\hline chick production & 18 & 11 & 9 & 30 & 16 & - estimates based on more than one count only \\
\hline adult survival & 20 & 11 & 8 & 44 & 15 & $\begin{array}{l}\text { - estimates derived from capture-recapture } \\
\text { modeling only }\end{array}$ \\
\hline
\end{tabular}


criterion corrected for small sample sizes $\left(\mathrm{AIC}_{\mathrm{C}}\right)$. As climatic effects do not have to be instantaneous, we considered time lags between zero and three years (i.e. NAO index values predating the demographic estimates by zero to three years). For comparison only, higher time lags were analysed using the same tests. The respective results are given in the Appendix only.

When mean life-history characteristics of the species were used as explanatory variables, they were inferred from the original studies wherever possible. Otherwise they were taken from the literature (Schreiber and Burger 2002a; supplemented with Poole and Gill 1992-2003, Rattiste and Lilleleht 1995, Wanless et al. 1996, Prévot-Julliard et al. 1998). In order to control for potential biases caused by differing time series lengths, we initially included this parameter as a covariate in all tests and dropped it from the models only if non-significant.

Because of the non-independence of biological species, combining data from more than one species requires phylogenetic-comparative analysis (Martins and Hansen 1996). We used Felsenstein's (1985) independent contrast method to accomplish that. Unfortunately, the phylogeny of seabirds is only incompletely known. Therefore, several parts of the phylogeny had to be represented by polytomies, most notably the information on relationships between the different seabird taxa within the Charadriiformes (i.e. auks, skuas, terns, gulls, and their respective allies) is partly contradictious and not yet easily reconciled (Mickevich and Parenti 1980, Sibley and Ahlquist 1990, Björklund 1994, Chu 1995, 1998, Ericson et al. 2003, Thomas et al. 2004). Rather than ignoring polytomies in our comparative analyses, we calculated all possible contrasts for each polytomy and used the mean value in subsequent analyses.

Phylogenies were available, at least with the resolution needed for our studies, for the Procellariidae (Viot et al. 1993, Nunn and Stanley 1998), the Alcidae (Strauch 1985, Moum et al. 1994, 2002, Friesen et al. 1996), the Laridae (Chu 1998, Crochet et al. 2000, 2002, Pons et al. 2005), and the basal branchings of the major seabird groups (Cracraft 1985, Sibley and Ahlquist 1990, Hedges and Sibley 1994, Siegel-Causey 1997).

As branch lengths were not reported in all studies just cited, and methodologies for estimating them were not always comparable among studies that did, we used approximations of branch lengths based upon the number of extant species belonging to each branch (Grafen 1989). Scaling by $\rho=0.25$ the branch lengths thus obtained (cf. Grafen 1989), resulted in contrasts whose distribution was fairly close to normal (Garland et al. 1992).

Further problems arise when contrasts are zero in one variable, because the sign of the contrast in the other variable becomes arbitrary in such cases (cf. Garland et al. 1992). It has been suggested to resolve this problem by using the mean of both possible values (that is to say: zero; Jennings et al. 1999). However, we suspected that the presence of several artificially created data points in the origin could inflate the degrees of freedom, so we excluded those contrasts altogether. Regressions of independent contrasts were forced through the origin (Garland et al. 1992).

Analyses were repeated with species and populations rather than contrasts as data points. Those procedures increased the sample size, but ignored phylogenetic correlations. The results did not differ much and are not further discussed. In the analyses that were based on species and independent contrasts, each species was represented by the average climatic responsiveness of its populations, weighted by the length of the time series.

Tables reporting the results of many such test results suffer from inflated type I error rates. Bonferroni or DunnŠidák corrections are sometimes used to take this fact into account, however these tests are overly conservative (Moran 2003). We corrected for the occurrence of type I errors by means of a re-sampling procedure (bootstrap): 6000 NAOlike time series were created by randomly drawing values from the original NAO time series at random. The same tests were carried out with these randomised data, and the real findings were compared to the simulated ones. The overall probabilities reported are the proportion of simulated results that obtained the same effects as, or stronger effects than, the results observed. In the Appendix, both row-wise, column-wise and table-wise probabilities are reported. In the main text only the latter are given, as they fully correct for the number of tests. To account for the intercorrelation between the explanatory variables, we also considered the first principal component of the six explanatory variables plus body mass.

All statistical calculations were carried out in the $R$ environment ( $\mathrm{R}$ development core team 2005), using functions written by one of us (H.S.) to perform phylogenetic-comparative analyses.

\section{Results}

106 time series were assembled for 23 species from 64 colonies, totalling 1128 yr of observation ("colony-years"). The position of the colonies used in this study is shown in Fig. 1.

\section{Magnitude of climatic responsiveness}

Many Atlantic seabird populations showed changes in their demographic rates that were correlated with the NAO index (Table 2). A species-wise overview of climatic responsivenesses is given in the Appendix (Table S2 and S3). The whole range of time lags considered $(0-3 \mathrm{yr})$ turned out to be relevant in at least some of the species. The mean time lag that maximized correlation with NAO across all species, was $1.1 \mathrm{yr}$ (median, $1 \mathrm{yr}$ ).

Averaged over all time lags, climate responsiveness in chick production varied between 0.02 (Calonectris diomedea, $\mathrm{n}_{\mathrm{S}}=1$ studies, $\mathrm{n}_{\mathrm{Y}}=10$ colony-years) and 0.50 (Sterna maxima, $\left.\mathrm{n}_{\mathrm{S}}=1, \mathrm{n}_{\mathrm{Y}}=4\right)$, and the unweighted mean was 0.18 . This value was only marginally higher than could be expected by chance $(p=0.095$, Table 2$)$, and was not significant at any single time lag. When considering only those time lags that maximized each species' responsiveness, the correlations were significant at the 0.05 level in $15 \%$ of the studies (11 out of 72) and a third of the species ( 8 out of $22)$. The respective unweighted mean climatic responsiveness 0.38 was marginally significant $(p=0.054)$. 


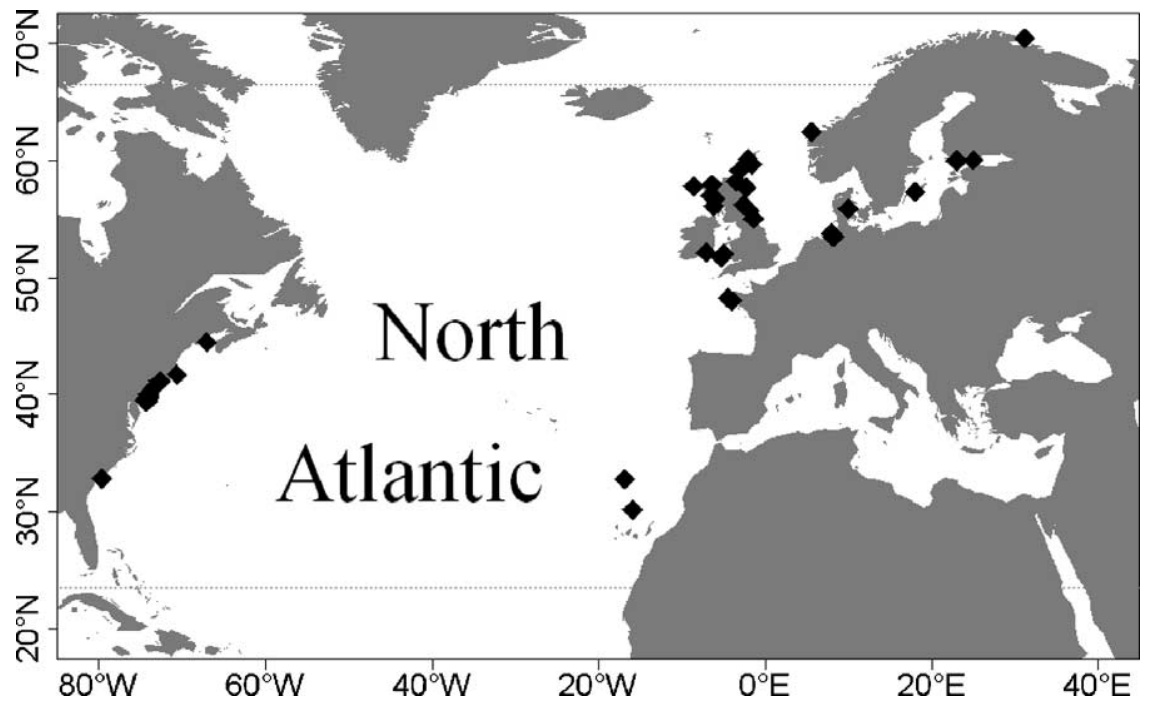

Fig. 1. Map showing the position of the 46 seabird breeding colonies included in the comparative analyses.

The corresponding figures for the species' climatic responsiveness in adult survival were lying between 0.04 (Larus fuscus, $\mathrm{n}_{\mathrm{S}}=2, \mathrm{n}_{\mathrm{Y}}=24$ ) and 0.29 (Stercorarius parasiticus, $\mathrm{n}_{\mathrm{S}}=1, \mathrm{n}_{\mathrm{Y}}=6$ ) with an unweighted mean of 0.13 . This value was not statistically significant. However, the responsiveness at time lag zero $(0.21)$ was $(\mathrm{p}=$ 0.0063 , Table 2). When only looking at the time lags that maximised each species' responsiveness, the correlations were significant at the 0.05 level in nearly a fourth of the studies ( 8 out of 34 ) and $40 \%$ of the species (7 out of 17). The mean responsiveness at those time lags was $0.31(\mathrm{p}=$ $0.18)$.

When considering the coefficient of correlation rather than of determination ( $r$ rather than $r^{2}$ ) of demographic rates with $\mathrm{NAO}$, the across-species means were less impressive $(-0.004$ for chick production, and -0.08 for adult survival), because positive and negative effects tended to cancel each other out.

Those findings were largely independent of the data sets used, i.e. they could be reproduced using both the restricted and the high quality data set. Both climatic responsivenesses and the proportion of significant results tended to decrease somewhat with the decreasing sample sizes, but the results described above held even for those data sets.
Across species, climatic responsiveness in chick production was highest at a time lag of three years, and in adult survival at zero years. However, there was no clear peak, i.e. many other time lags were almost equally important. The same pattern was found for the restricted data set, and for adult survival in the high quality data set. The highest mean responsiveness (0.14) in chick production in the high quality data set was found at a time lag of two years.

\section{Correlates of climate responsiveness}

Figure 2 suggests that the species responding most (or least) are not spread totally at random throughout the bird phylogeny: high and low climatic responsiveness of adult survival seems to be concentrated in certain taxa. Terns and cormorants were among the most responsive species, while auks and the gannet were the least responsive ones. The phylogenetic correlation (or inertia) was quite high and barely significant $\left(\mathrm{r}^{2}=0.82, \mathrm{p}=0.048\right.$; derived from a bootstrapping procedure that reordered the observed responsivenesses 12000 times). The corresponding results for climatic responsiveness in chick production were even weaker $\left(\mathrm{r}^{2}=0.65, \mathrm{p}=0.45\right)$.

Table 2. Responsiveness to climatic variation in two demographic traits of 23 species of North Atlantic seabirds. Responsiveness to climate estimated for time lags between zero and three years - was defined as the coefficient of determination derived from Pearson's correlation (see Material and methods). Given are the number of studies with significant correlations, the mean responsiveness (see Table S2 and S3 for species-wise results), and the significance level derived from a re-sampling simulation.

\begin{tabular}{|c|c|c|c|c|}
\hline \multicolumn{5}{|c|}{ Time lag } \\
\hline 0 & 1 & 2 & 3 & $0-3$ \\
\hline 4 & 6 & 4 & 3 & 17 \\
\hline 0.16 & 0.19 & 0.19 & 0.18 & 0.18 \\
\hline 0.40 & 0.18 & 0.18 & 0.26 & 0.095 \\
\hline 4 & 4 & 1 & 2 & 11 \\
\hline 0.21 & 0.11 & 0.09 & 0.12 & 0.13 \\
\hline 0.0063 & 0.66 & 0.88 & 0.57 & 0.31 \\
\hline
\end{tabular}




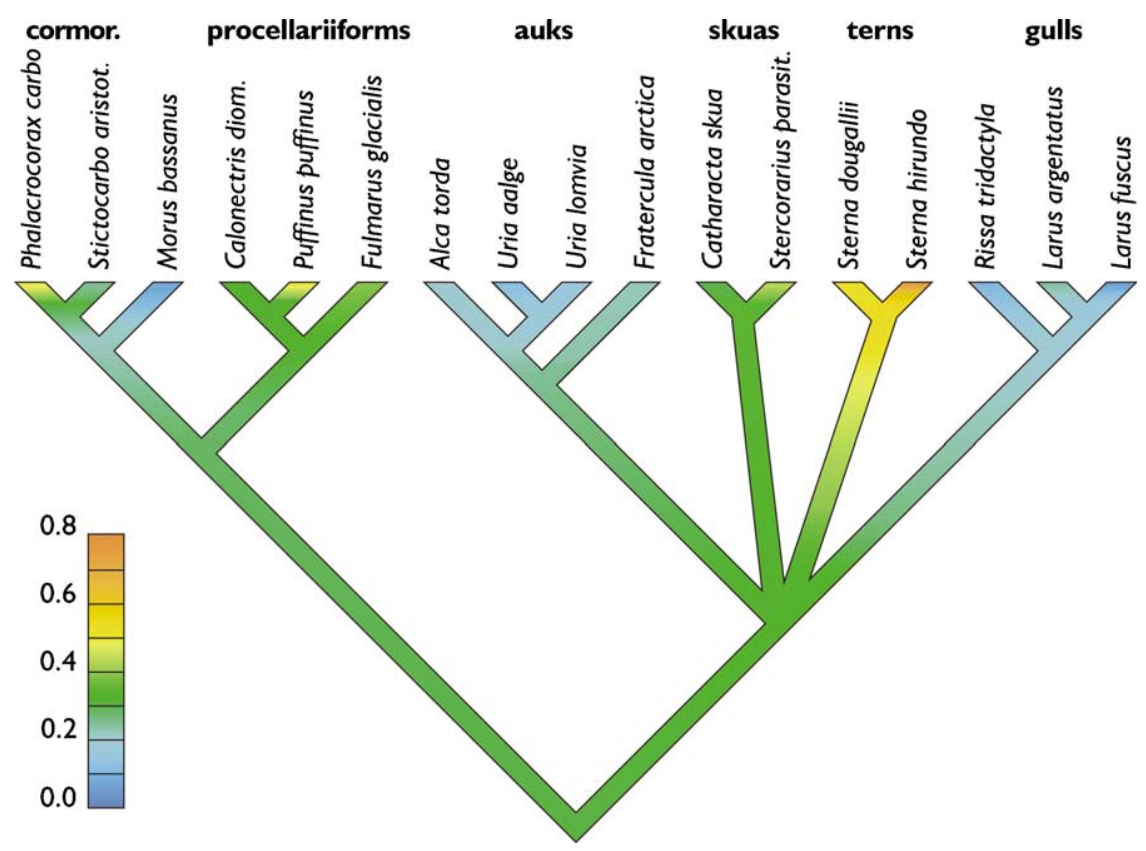

Fig. 2. A phylogenetic tree of seabirds showing the distribution of climatic responsiveness in adult survival, i.e. the variance in adult survival explained by the NAO index. Colours represent coefficients of determination $\left(\mathrm{r}^{2}\right)$. In yellowish branches, survival and NAO are highly correlated, in bluish branches only weakly so. (Branches for which no data were available have been pruned.)

Still, correlates may be able to explain the distribution of climatic responsivenesses across taxa. In the next step of the analysis, therefore, the measures of responsiveness to climatic variation obtained earlier were subjected to further scrutiny. Table 3 summarizes the explanatory variables examined in order to account for the variation in climatic responsiveness of chick production and adult survival. Some interesting tendencies emerged. Clutch size explained 35\% of the variance in climatic responsiveness of adult survival $(p=0.033$; Fig. 3a). This significant result is not at all unlikely given the number of tests (twelve), however. Due to low sample size it could not be reproduced using the high-quality dataset either (Fig. 3b). Among the ecological explanatory variables, the highest correlation was between foraging distance and climatic responsiveness in adult survival, but it was not statistically significant $\left(r^{2}=0.22\right.$, $p=0.14)$. We also considered as an explanatory variable the first principal component of body mass, the four demographic and the two ecological explanatory variables. This variable was positively correlated to measures of fecundity and negatively so to measures of longevity and feeding range. In other words, high values of the principal component correspond to comparatively "fast" life histories. The effect of this principal component was marginally significant in the case of climatic responsiveness in adult survival only $(\mathrm{p}=0.089)$.

When considering the signs of the correlations, it appeared that many of them were, biologically speaking, in the same direction: climatic responsiveness decreased when measures of longevity and foraging range increased (and measures of fecundity decreased). A closer inspection shows that this is because five out of six tests involving climatic responsiveness in adult survival as the dependent variable were in the same "biological direction". This finding would be unlikely as judged by a sign test $(\mathrm{p}=$ 0.031). However, those patterns were weaker when using

Table 3. Correlations between the responsiveness to climatic variability in offspring production and adult survival, respectively, and six explanatory variables at the time lag that maximizes each species's climatic responsiveness. Values provided are the correlation coefficients between the interspecific variation of the climatic responsiveness and the explanatory variables. The sample size (n) is the number of phylogenetically independent contrasts (see Material and methods). One correlation $\left(^{*}\right)$ was significant at the $5 \%$ level, two others $\left({ }^{+}\right.$) marginally significant $(0.1>p>0.05)$.

\begin{tabular}{lcccc}
\hline Explanatory variable & \multicolumn{2}{c}{ Climatic responsiveness } \\
\cline { 2 - 4 } & \multicolumn{2}{c}{ in offspring production } & & in adult survival \\
\cline { 2 - 4 } & $\mathrm{n}$ & $\mathrm{r}$ & $\mathrm{n}$ & $\mathrm{r}$ \\
\hline clutch size & 14 & -0.294 & 13 & $+0.592^{*}$ \\
chick production & 19 & -0.098 & 14 & $+0.428^{+}$ \\
age at maturity & 19 & -0.215 & -0.232 \\
adult survival & 19 & -0.348 & 14 & -0.204 \\
foraging distance & 19 & +0.129 & 13 & -0.121 \\
diving depth & 19 & +0.152 & 14 & +0.202 \\
principal component & 19 & & $+0.418^{+}$ \\
\hline
\end{tabular}



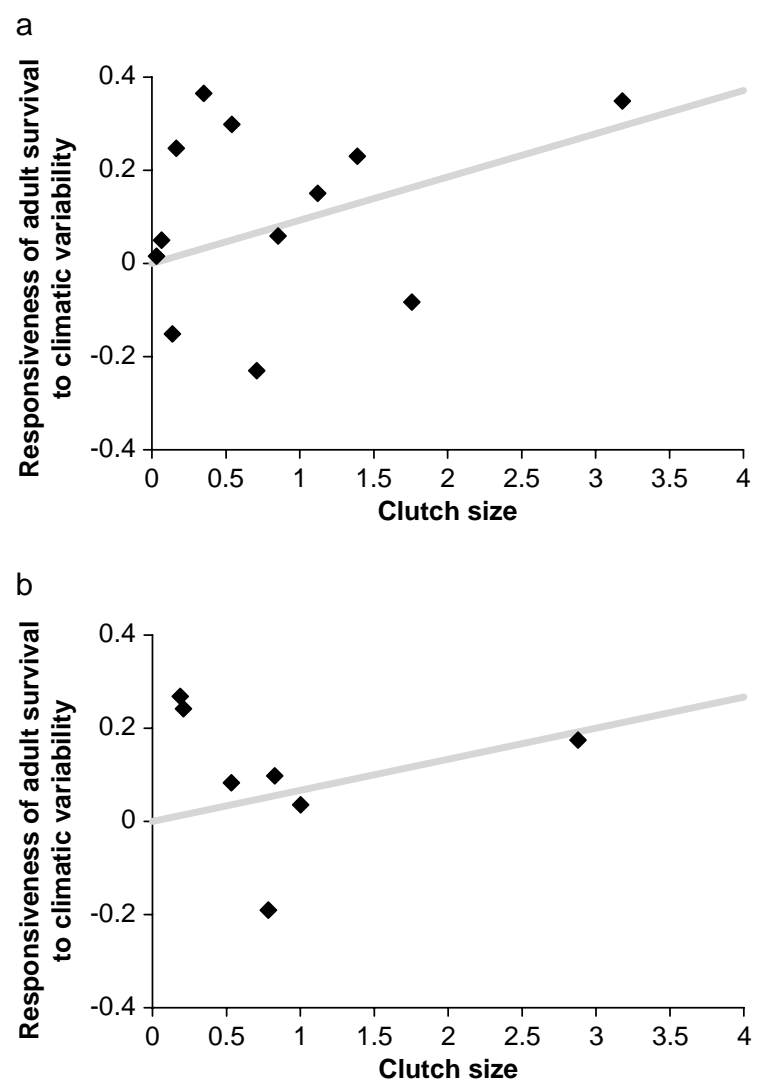

Fig. 3. Correlations between a species's mean clutch size and its responsiveness to climatic variation in adult survival. (a) Data come from the standard dataset (see Material and methods), and the correlation is significant. (b) Data come from the high-quality dataset, and the correlation is not significant. Values on both axes are phylogenetically independent contrasts. The regression line is forced through the origin (see Material and methods).

the restricted or the high-quality data sets, and can thus not be said to be especially robust.

In addition to the time lag that maximizes each species' climatic responsiveness, correlations were also tested at fixed time lags, i.e. applying the same time lags across all species. The results of this analysis are given in the Appendix (Table S4). The number of significant correlations was not higher than expected by chance ( 6 out of 48 tests performed, tablewised $\mathrm{p}=0.20$ ). Considering the principal component, its overall explanatory value was significant $(\mathrm{p}=0.031)$, but not so in adult survival $(p=0.10)$. This pattern could furthermore be confirmed with the restricted data set, but disappeared in the high-quality one. A common finding in all three data sets considered was that relationships in the above-mentioned direction (climatic responsiveness positively related to measures of fecundity) cumulated around a time lag of two to three years. Correlations with the opposite sign, however, cumulated at a zero time lag.

\section{Discussion}

We provided a comparative analysis of some factors that might explain variation in responsiveness to climatic variability in life-history characteristics of seabirds. Our findings highlight several important aspects of seabird evolutionary ecology: 1) the interspecific approach allows an answer to the question whether a significant effect of climate on seabirds occurs more often than expected by chance. This was not the case overall, although a response seems to be the rule rather than the exception in certain taxa. 2) Many of those effects in single species are lagged by several years in relation to the climatic signal. 3) There were some indications that the species with high climatic responsiveness in survival (but not production) are not scattered at random throughout the seabird phylogeny. 4) It is possible that biological characteristics of the species can predict their climatic responsiveness.

We discuss those aspects in turn.

\section{Magnitude of climatic responsiveness}

By analyzing over 100 time series from 23 seabirds species spread across the entire North Atlantic, we found that a correlation between demographic parameters (chick production, adult survival) and the winter North Atlantic Oscillation (NAO) index was not more common than expected by chance alone. If summed over the four time lags considered $(0-3 \mathrm{yr})$, significant climate effects were found in eight species. However, due to the high number of tests necessary, overall statistical tests rejected a climatic effect, although it was marginally significant with respect to chick production, and reached significance for one time lag (viz., zero) in adult survival.

A multitude of studies has documented effects of climate on different aspects of reproductive biology and/or survival of seabirds, predominantly in oceanic regions influenced by the El Niño-Southern Oscillation (Barber and Chavez 1983, Duffy 1990, Chastel et al. 1993). Also in the North Atlantic, evidence of climate effects is present, such as an effect of sea surface temperature on breeding phenology (Barrett 2001) and on breeding success (Durant et al. 2003); and of air temperature on recruitment rates (Thompson and Ollason 2001). Effects of the NAO on seabirds are still comparatively poorly studied, however recent findings have documented the existence of NAOrelated responses in breeding phenology, breeding success, adult survival, and the size of the breeding population (Durant et al. 2004a, Frederiksen et al. 2004, Harris et al. 2005, Sandvik et al. 2005, Votier et al. 2005, Crespin et al. 2006).

Few studies have so far attempted at reviewing and synthesizing the evidence available (Reid et al. 1999, Thompson and Grosbois 2002, Durant et al. 2004b). However, no earlier attempt has been made at quantifying interspecifically whether the number of species that show responses to climate is higher than expected by chance. While studies analysing climate effects in single species may suffer from the "file drawer problem" or publication bias (Bauchau 1997, Silvertown and McConway 1997), the current study utilised a large number of time series, many of which had been published for reasons unrelated to climate. Our sample is thus most probably more representative and reliable than the subsample of studies that explicitly report climatic effects in the species studied. 
The mechanisms underlying the correlation between the NAO and seabird biology can take a number of different pathways. In any case, the NAO is not the causal link itself (Ottersen et al. 2001), but is a useful proxy for meteorological and oceanographic phenomena such as air or sea surface temperature, wind speed and strength of ocean currents (Hurrell et al. 2003, Hurrell and Dickson 2004). Those parameters may in turn affect seabirds both directly and indirectly. Each trophic level starting with phytoplankton and up to top predators can be affected by climate itself and by the integrated effects of climate on the trophic levels below (Dalpadado et al. 2003, Alheit et al. 2005, Ferguson et al. 2005). A fine example by Hjermann et al. (2004) illustrates how effects can be mediated through the food chain by elucidating the interactions between three Barents Sea fish species at different trophic levels with each other and the NAO: all fish species are affected by NAO (via the inflow of Atlantic water into the Barents Sea) on a unlagged basis; in addition capelin Mallotus villosus and, to a lesser extent, herring Clupea harengus experience a lagged topdown effect through predation from higher trophic levels. As all three fish species also are important prey species of the large seabird colonies found in this area (Barrett 2002), it is not surprising that those seabirds respond to both availability of fish and thus indirectly to climate variables (Sandvik et al. 2005). Also direct responses of seabirds to adverse weather conditions are well documented (Hudson 1985, Schreiber 2002), which in turn are highly correlated with large-scale patterns such as the NAO.

\section{Time lags}

The time lags at which the climatic responsiveness was most pronounced varied widely, both between species and between colonies within species. Time lags between the climatic signal and the demographic response can arise for different reasons. The most important of these is that the climate effect can be indirect and mediated through the food chain rather than a direct influence of meteorological parameters. This is in accordance with theory (Ashmole 1963, Birkhead and Furness 1985) and empirical findings (Barbraud and Weimerskirch 2003, Jenouvrier et al. 2003, Sandvik et al. 2005) on the causes of seabird mortality.

It is hard to imagine time lags of more than approximately three years to be caused by trophic delays. Disturbingly, however, climatic responsiveness in offspring production was more pronounced at time lags outside the range we considered as potentially biologically meaningful (0-3 yr, Appendix, Table S2 and S3). Another cause of time lags might be caused by cohort effects due to the high age at recruitment of seabirds. This explanation does not seem especially likely, however, so that the patterns identified in Appendix, Table S2 and S3 probably are largely due to type I errors (noise). The most important time lag in climatic responsiveness of adult survival is much shorter (zero, Table 3 ), which is compatible with both direct and trophic effects.

\section{Correlates of climate responsiveness}

As regards the magnitude of climate responsiveness, we were interested to see whether this variable would be clustered taxonomically and/or whether it would be correlated with life-history and/or ecological characteristics of the species concerned. Two measures of fecundity and of longevity were considered, viz. clutch size, offspring production, age at maturity and annual adult survival. In addition, two ecological variables related to feeding range were tested, namely foraging distance and diving depth. The patterns were weak and not robust, in that they were not visible in all data sets considered.

There was a tendency, however, that climatic responsiveness, especially in adult survival, was positively correlated with measures of fecundity, and negatively so with measures of longevity and feeding range. If this pattern is not an artefact, the signs would make biological sense. It can be derived from life-history theory that species should be the more reluctant to invest into any specific breeding attempt at the cost of future ones, the lower their fecundity and the higher their adult survival are (Wooller et al. 1992, Sæther and Bakke 2000, Gaillard and Yoccoz 2003). This is because, in long-lived species, adult survival is the lifehistory trait which has the highest elasticity, i.e. which is under the strongest selection pressure (Gadgil and Bossert 1970, Lebreton and Clobert 1991, Stearns 1992). A decrease in responsiveness to climate with increasing longevity would be compatible with those findings.

One reason that the climatic responsiveness in chick production was less phylogenetically structured than the climatic responsiveness in adult survival (and that the corresponding interspecific variation was harder to account for using explanatory variables), may also be found in lifehistory theory: the more long-lived a species is, the less variable, on average, is its survival expected to be. On the other hand, the same does not apply to the offspring production of those long-lived species. Their breeding success may be at least as variable as that of more shortlived species, since they can sustain high survival only because it is traded off by highly flexible investment into offspring (Drent and Daan 1980). In other words, adult survival is canalised against temporal variability (Gaillard and Yoccoz 2003; cf. Sæther and Bakke 2000).

As regards feeding biology, it has been shown by Furness and co-workers that birds with a larger feeding range also have a larger potential to find prey, and are more flexible towards the local availability or unavailability of prey fish (Furness and Ainley 1984, Furness and Barrett 1991, Furness and Tasker 2000). This can explain why their adult survival may be slightly less sensitive to climatic variability. There was no comparable effect on the climatic responsiveness in chick production.

\section{Methodological issues}

The proportion of variation in demographic traits explained in terms of NAO is here referred to as climatic responsiveness. One reason to define responsiveness in this way, i.e. as the coefficient of determination rather than as its square root, the correlation coefficient, was that the sign of relations between biological phenomena and the NAO has been shown to vary widely even within species and on comparatively small geographical scales (Mysterud et al. 2000, Sæther et al. 2003; cf. Harris et al. 2005). This is also 
corroborated by our findings. Therefore, responsiveness to climatic variation may be more conveniently viewed a propensity, rather than an attribute, of a given species. That is to say that the potential absolute amount of responsiveness may be species-specific, while the actual amount and even sign of the correlation coefficient with climatic parameters depends on much more than the species's characteristics, such as the location of the colony and the ecology of the main local food source. The coefficient of determination has the advantage of always being positive, so that averaging several values does not incorporate the danger of nullifying otherwise large effects at different colonies. Further research may make it possible also to address the signs of the correlations.

Differences between breeding colonies of the same species are presumably widespread but represent nevertheless an underappreciated phenomenon (Frederiksen et al. 2005, Harris et al. 2005). The current study may also have suffered from the fact that for most species data from only a few colonies were available. This may have introduced noise into the analyses, if the few colonies (or single colony) of a species showed responses that are not representative for the respective species as a whole.

The reason for the varying signs of NAO effects lies in the nature of the NAO, viz. that it exerts different effects in different geographic regions: for instance sea surface temperatures are positively correlated to the NAO index in the North Sea and the southern part of the North Atlantic, but negatively correlated in the northern parts of the North Atlantic (Hurrell and Dickson 2004). Using sea surface temperatures might thus be a promising alternative to defining climatic responsiveness in terms of correlation with NAO index values, especially as far as the response in chick production is concerned (Sandvik et al. in press). As it is often very poorly known were seabirds are outside the breeding season, sea surface temperatures may be less applicable in studying responses of adult survival. Nevertheless, sea surface temperatures have been shown to affect adult survival in a couple of seabird species (Barbraud and Weimerskirch 2001, 2003, Jenouvrier et al. 2003, Harris et al. 2005, Sandvik et al. 2005), so looking for such effects is certainly worthwhile.

A final concern might be the quality of the time series underlying our analyses. Many of the studies do not report confidence intervals for their annual estimates, and several studies applied methodologies that may result in biased estimates (such as a single counts of fledglings to determine offspring production, or the failure to use capture-markrecapture methods in determining adult survival). While we are aware of the fact that this introduces more noise into the data than may be desirable, accepting those time series for what they are seems still to be a better alternative than discarding the huge amounts of data that generations of field biologists have accumulated. Even though the data quality is not ideal, using this dataset in a comparative search for general patterns is currently the best use to which it can be put. Most time series were in fact recorded for reasons entirely unrelated to climatic issues. There is thus no reason to expect that the noise contained in this data base is systematically biased with regard to the questions we have addressed (i.e. no "publication bias", see above).
Furthermore, we used a smaller, high-quality dataset to double-check our findings, but sample sizes in this dataset were too small to give conclusive results.

\section{Conclusion and outlook}

To conclude, we documented some effects of climatic variability, as measured by the NAO index, in Atlantic seabirds. Furthermore, our investigation indicated that certain life-history characteristics may give clues as to why some species are more responsive to climate than others. However, most findings were not especially robust, most likely because our sample of species - although larger than in any previous study - was still insufficient to decide those questions. The effects found in adult survival were only significant if unlagged, while the effects of climate on offspring production were weak at best and most pronounced at long time lags. This underlines the importance of long-term data series. We would like to urge researchers to publish all long-term datasets, independently of whether or not the time series reveals climatic or any other ecological effects. Such effects may be non-significant in single studies, but lead to the emergence of interesting patterns if analysed comparatively.

Our analyses were exploratory (rather than confirmatory) sensu Anderson et al. (2001), so we did not expect to give final answers to the questions raised. Rather we attempted at laying the ground for future study by means of description of the patterns that are contained in the data base - both to encourage others to approach existing data in the same comparative way, and in order to expose areas where research scrutinizing particular findings could be rewarding, a process which probably will corroborate some of our findings, most certainly falsify others, and hopefully stimulate alternative interpretations.

So far, few interspecific studies have been carried out (Kitaysky and Golubova 2000, Barbraud and Weimerskirch 2001, Inchausti et al. 2003, Jenouvrier et al. 2005), and this one is the first to approach the problem comparatively. Future studies may try to increase the spatial resolution and to address the effect of other meteorological parameters such as sea surface temperature. However, this requires that the within-species variation be taken into account, which is currently impossible using phylogenetic-comparative methods. Also the consideration of trophic level as an explanatory variable seems to be very promising (cf. Ainley et al. 1995a, b, Kitaysky and Golubova 2000, Kitaysky et al. 2000). This is not easy to address in an interspecific framework either because the same species may feed on different prey species in different parts of its breeding range. We therefore believe that a combination of both descriptive and comparative studies will most certainly prove valuable.

Acknowledgements - The study was financially supported by the Research Council of Norway and by the Norwegian Inst. for Nature Research. We thank E. Schreiber for kindly allowing us to use her data set on seabird breeding biology (Schreiber and Burger 2002a). E. Cooch, T. Coulson, S. A. Hatch, I. P. F. Owens and 
B.-E. Sæther and anonymous reviewers have made very useful comments on the manuscript.

\section{References}

Aebischer, N. J. et al. 1990. Parallel long-term trends across four marine trophic levels and weather. - Nature 347: 753-755.

Ainley, D. G. and Divoky, G. J. 2001. Seabird responses to climate change. - In: Steele, J. H. et al. (eds), Encyclopedia of ocean sciences. Academic Press, pp. 2669-2677.

Ainley, D. G. et al. 1995a. Upper trophic level predators indicate interannual negative and positive anomalies in the California Current food web. - Mar. Ecol. Prog. Ser. 118: 69-79.

Ainley, D. G. et al. 1995b. Variations in marine bird communities of the California Current, 1986-1994. - Calif. Coop. Ocean. Fish. Investig. Rep. 36: 72-77.

Alheit, J. et al. 2005. Synchronous ecological regime shifts in the central Baltic and the North Sea in the late 1980s. - Int. Counc. Explor. Sea J. Mar. Sci. 62: 1205-1215.

Anderson, D. R. et al. 2001. Suggestions for presenting the results of data analyses. - J. Wildl. Manage. 65: 373-378.

Ashmole, N. P. 1963. The regulation of numbers of tropical oceanic birds. - Ibis 103b: 458-473.

Barber, R. T. and Chavez, F. P. 1983. Biological consequences of El Niño. - Science 222: 1203-1210.

Barbraud, C. and Weimerskirch, H. 2001. Emperor penguins and climate change. - Nature 411: 183-186.

Barbraud, C. and Weimerskirch, H. 2003. Climate and density shape population dynamics of a marine top predator. - Proc. R. Soc. B 270: 2111-2116.

Barnston, A. G. and Livezey, R. E. 1987. Classification, seasonality and persistence of low-frequency atmospheric circulation patterns. - Monthly Weather Rev. 115: 1083-1126.

Barrett, R. T. 2001. The breeding demography and egg size of north Norwegian Atlantic puffins Fratercula arctica and razorbills Alca torda during 20 years of climatic variability. - Atl. Seabirds 3: 97-112.

Barrett, R. T. 2002. Atlantic puffin Fratercula arctica and common guillemot Uria aalge chick diet and growth as indicators of fish stocks in the Barents Sea. - Mar. Ecol. Prog. Ser. 230: 275287.

Bauchau, V. 1997. Is there a "file drawer problem" in biological research? - Oikos 79: 407-409.

Bennett, P. M. and Owens, I. P. F. 2002. Evolutionary ecology of birds: life histories, mating systems, and extinction. - Oxford Univ. Press.

Birkhead, T. R. and Furness, R. W. 1985. Regulation of seabird populations. - In: Sibly, R. M. and Smith, R. H. (eds), Behavioural ecology: ecological consequences of adaptive behaviour. Blackwell, pp. 145-167.

Björklund, M. 1994. Phylogenetic relationships among Charadriiformes: reanalysis of previous data. - Auk 111: 825-832.

Chastel, O. et al. 1993. High annual variability in reproductive success and survival of an Antarctic seabird, the snow petrel Pagodroma nivea: a 27-year study. - Oecologia 94: 278-285.

Chu, P. C. 1995. Phylogenetic reanalysis of Strauch's osteological data set for the Charadriiformes. - Condor 97: 174-196.

Chu, P. C. 1998. A phylogeny of the gulls (Aves: Larinae) inferred from osteological and integumentary characters. - Cladistics 14: 1-43.

Cracraft, J. 1985. Monophyly and phylogenetic relationships of the Pelecaniformes: a numerical cladistic analysis. - Auk 102: 834-853.

Crespin, L. et al. 2006. Recruitment to a seabird population depends on environmental factors and on population size. $-\mathrm{J}$. Anim. Ecol. 75: 228-238.
Crochet, P.-A. et al. 2000. Molecular phylogeny and plumage evolution in gulls (Larini). - J. Evol. Biol. 13: 47-57.

Crochet, P.-A. et al. 2002. Systematics of large white-headed gulls: patterns of mitochondrial DNA variation in western European taxa. - Auk 119: 603-620.

Dalpadado, P. et al. 2003. Zooplankton biomass variation in relation to climate conditions in the Barents Sea. - Polar Biol. 26: 233-241.

Drent, R. H. and Daan, S. 1980. The prudent parent: energetic adjustments in avian breeding. - Ardea 68: 225-252.

Duffy, D. C. 1990. Seabirds and the 1982-1984 El NiñoSouthern Oscillation. - In: Glynn, P. W. (ed.), Global ecological consequences of the 1982-83 El Niño-Southern Oscillation. Elsevier, pp. 395-415.

Durant, J. M. et al. 2003. Trophic interactions under climate fluctuations: the Atlantic puffin as an example. - Proc. R. Soc. B 270: 1461-1466.

Durant, J. M. et al. 2004a. Regime shifts in the breeding of an Atlantic puffin population. - Ecol. Lett. 7: 388-394.

Durant, J. M. et al. 2004b. Marine birds and climate fluctuation in the North Atlantic. - In: Stenseth, N. C. et al. (eds), Marine ecosystems and climate variation: the North Atlantic - a comparative perspective. Oxford Univ. Press, pp. 95-105.

Ericson, P. G. P. et al. 2003. Inter-familial relationships of the shorebirds (Aves: Charadriiformes) based on nuclear DNA sequence data. - BMC Evol. Biol. 3: 1-14.

Erikstad, K. E. et al. 1998. On the cost of reproduction in longlived birds: the influence of environmental variability. - Ecology 79: 1781-1788.

Felsenstein, J. 1985. Phylogenies and the comparative method. - Am. Nat. 125: 1-15.

Ferguson, S. H. et al. 2005. Climate change and ringed seal (Phoca hispida) recruitment in western Hudson Bay. - Mar. Mammal. Sci. 21: 121-135.

Frederiksen, M. et al. 2004. The role of industrial fisheries and oceanographic change in the decline of North Sea black-legged kittiwakes. - J. Appl. Ecol. 41: 1129-1139.

Frederiksen, M. et al. 2005. Inter-population variation in demographic parameters: a neglected subject? - Oikos 111: 209-214.

Friesen, V. L. et al. 1996. Phylogenetic relationships within the Alcidae (Charadriiformes: Aves) inferred from total molecular evidence. - Mol. Biol. Evol. 13: 359-367.

Furness, R. W. and Ainley, D. G. 1984. Threats to seabird populations presented by commercial fisheries. - In: Croxall, J. P. et al. (eds), Status and conservation of the world's seabirds. Int. Counc. Bird Preserv., pp. 701-708.

Furness, R. W. and Barrett, R. T. 1991. Ecological responses of seabirds to reductions in fish stocks in north Norway and Shetland. - In: Furness, R. W. and Nettleship, D. N. (eds), Proceedings of the symposium on seabirds as monitors of changing marine environments. Acta XX Congr. Int. Ornithol., pp. 2241-2245.

Furness, R. W. and Tasker, M. L. 2000. Seabird-fishery interactions: quantifying the sensitivity of seabirds to reductions in sandeel abundance, and identification of key areas for sensitive seabirds in the North Sea. - Mar. Ecol. Prog. Ser. 202: 253-264.

Gadgil, M. and Bossert, W. H. 1970. Life historical consequences of natural selection. - Am. Nat. 104: 1-24.

Gaillard, J.-M. and Yoccoz, N. G. 2003. Temporal variation in survival of mammals: a case of environmental canalization? - Ecology 84: 3294-3306.

Garland, T., Jr et al. 1992. Procedures for the analysis of comparative data using phylogenetically independent contrasts. - Syst. Biol. 41: 18-32.

Gille, S. T. 2002. Warming of the Southern Ocean since the 1950s. - Science 295: 1275-1277. 
Grafen, A. 1989. The phylogenetic regression. - Phil. Trans. R. Soc. B 326: 119-157.

Harris, M. P. et al. 2005. Effect of wintering area and climate on the survival of adult Atlantic puffins Fratercula arctica in the eastern Atlantic. - Mar. Ecol. Prog. Ser. 297: 283-296.

Hedges, S. B. and Sibley, C. G. 1994. Molecules vs. morphology in avian evolution: the case of the "pelecaniform" birds. - Proc. Nat. Acad. Sci. USA 91: 9861-9865.

Hjermann, D. Ø. et al. 2004. Indirect climatic forcing of the Barents Sea capelin: a cohort effect. - Mar. Ecol. Prog. Ser. 273: 229-238.

Hudson, P. J. 1985. Population parameters for the Atlantic Alcidae. - In: Nettleship, D. N. and Birkhead, T. R. (eds), The Atlantic Alcidae: the evolution and biology of the auks inhabiting the Atlantic Ocean and adjacent water areas. Academic Press, pp. 233-261.

Hull, D. L. 1999. The use and abuse of Sir Karl Popper. - Biol. Philos. 14: 481-504.

Hunt, B. G. and Elliott, T. I. 2004. Interaction of climatic variability with climatic change. - Atmos.-Ocean 42: 145172.

Hurrell, J. W. 1995. Decadal trends in the North Atlantic Oscillation: regional temperatures and precipitation. - Science 269: 676-679.

Hurrell, J. W. 2005. Climate indices. - <http://www.cgd. ucar.edu/cas/jhurrell/indices.html $>$.

Hurrell, J. W. and Dickson, R. R. 2004. Climate variability over the North Atlantic. - In: Stenseth, N. C. et al. (eds), Marine ecosystems and climate variation: the North Atlantic - a comparative perspective. Oxford Univ. Press, pp. 15-31.

Hurrell, J. W. et al. 2001. The North Atlantic Oscillation. - Science 291: 603-605.

Hurrell, J. W. et al. 2003. An overview of the North Atlantic Oscillation. - In: Hurrell, J. W. et al. (eds), The North Atlantic Oscillation: climatic significance and environmental impact. Am. Geophys. Union, pp. 1-35.

Inchausti, P. et al. 2003. Inter-annual variability in the breeding performance of seabirds in relation to oceanographic anomalies that affect the Crozet and the Kerguelen sectors of the Southern Ocean. - J. Avian Biol. 34: 170-176.

Jennings, S. et al. 1999. Predicting the vulnerability of tropical reef fishes to exploitation with phylogenies and life histories. - Conserv. Biol. 13: 1466-1475.

Jenouvrier, S. et al. 2003. Effects of climate variability on the temporal population dynamics of southern fulmars. - J. Anim. Ecol. 72: 576-587.

Jenouvrier, S. et al. 2005. Long-term contrasted responses to climate of two Antarctic seabird species. - Ecology 86: 28892903.

Kitaysky, A. S. and Golubova, E. G. 2000. Climate change causes contrasting trends in reproductive performance of planktivorous and piscivorous alcids. - J. Anim. Ecol. 69: 248-262.

Kitaysky, A. S. et al. 2000. Resource allocation in breeding seabirds: response to fluctuations in their food supply. - Mar. Ecol. Prog. Ser. 206: 283-296.

Lebreton, J.-D. and Clobert, J. 1991. Bird population dynamics, management, and conservation: the role of mathematical modelling. - In: Perrins, C. M. et al. (eds), Bird population studies: relevance to conservation and management. Oxford Univ. Press, pp. 105-125.

Levitus, S. et al. 2000. Warming of the world ocean. - Science 287: 2225-2229.

Martins, E. P. and Hansen, T. F. 1996. The statistical analysis of interspecific data: a review and evaluation of phylogenetic comparative methods. - In: Martins, E. P. (ed.), Phylogenies and the comparative method in animal behavior. Oxford Univ. Press, pp. 22-75.
Mayr, E. 1988. Toward a new philosophy of biology: observations of an evolutionist. - Harvard Univ. Press.

Mickevich, M. F. and Parenti, L. R. 1980. [Book review of] The phylogeny of of the Charadriiformes (Aves) [by Joseph G. Strauch, Jr]. - Syst. Zool. 29: 108-113.

Moran, M. D. 2003. Arguments for rejecting the sequential Bonferroni in ecological studies. - Oikos 100: 403-405.

Moum, T. et al. 1994. Phylogeny and evolution of the auks (subfamily Alcinae) based on mitochondrial DNA sequences. - Proc. Nat. Acad. Sci. USA 91: 7912-7916.

Moum, T. et al. 2002. Mitochondrial DNA sequence evolution and phylogeny of the Atlantic Alcidae, including the extinct great auk (Pinguinus impennis). - Mol. Biol. Evol. 19: 14341439.

Mysterud, A. et al. 2000. Relationships between sex ratio, climate and density in red deer: the importance of spatial scale. $-\mathrm{J}$. Anim. Ecol. 69: 959-974.

Nunn, G. B. and Stanley, S. E. 1998. Body size effects and rates of cytochrome b evolution in tube-nosed seabirds. - Mol. Biol. Evol. 15: 1360-1371 [+ Corrigendum (2000) 17: 1774].

Ottersen, G. et al. 2001. Ecological effects of the North Atlantic Oscillation. - Oecologia 128: 1-14.

Pons, J.-M. et al. 2005. Phylogenetic relationships within the Laridae (Charadriiformes: Aves) inferred from mitochondrial markers. - Mol. Phylogen. Evol. 37: 686-699.

Poole, A. and Gill, F. (eds) 1992-2003. The birds of North America: life histories for the 21 st century. - Acad. Nat. Sci. and Am. Ornithol. Union.

Prévot-Julliard, A.-C. et al. 1998. Re-evalution of adult survival of black-headed gulls (Larus ridibundus) in presence of recapture heterogeneity. - Auk 115: 85-95.

$\mathrm{R}$ development core team. 2005. R: a language and environment for statistical computing, version 2.1.1. - R Found. Stat. Comput., <http://www.r-project.org $>$.

Rattiste, K. and Lilleleht, V. 1995. Survival rates of breeding common gulls in Estonia. - J. Appl. Stat. 22: 1057-1062.

Reid, J. B. et al. 1999. Evidence for decadal scale variations in seabird population ecology and links with the North Atlantic Oscillation. - In: Furness, R. W. and Tasker, M. L. (eds), Diets of seabirds and consequences of changes in food supply. Int. Counc. Explor. Sea, pp. 47-50.

Sæther, B.-E. and Bakke, Ø. 2000. Avian life history variation and contribution of demographic traits to the population growth rate. - Ecology 81: 642-653.

Sæther, B.-E. et al. 2003. Climate variation and regional gradients in population dynamics of two hole-nesting passerines. - Proc. R. Soc. B 270: 2397-2404.

Sandvik, H. 2001. Dyrenes evolusjon - en innføring i systematisk zoologi og dyrenes stamtre. - Tapir.

Sandvik, H. et al. 2005. The effect of climate on adult survival in five species of North Atlantic seabirds. - J. Anim. Ecol. 74: 817-831.

Sandvik, H. et al. in press. A latitudinal gradient in climate effects on seabird demography: results from interspecifc analyses. - Global Change Biol.

Schreiber, E. A. 2002. Climate and weather effects on seabirds. In: Schreiber, E. A. and Burger, J. (eds), Biology of marine birds. CRC, pp. 179-215.

Schreiber, E. A. and Burger, J. 2002a. Data on life-history characteristics, breeding range, size and survival for seabird species. - In: Schreiber, E. A. and Burger, J. (eds), Biology of marine birds. CRC, pp. 665-685.

Schreiber, E. A. and Burger, J. (eds) 2002b. Biology of marine birds. - CRC.

Sibley, C. G. and Ahlquist, J. E. 1990. Phylogeny and classification of birds: a study in molecular evolution. - Yale Univ. Press. 
Siegel-Causey, D. 1997. Phylogeny of the Pelecaniformes: molecular systematics of a privative group. - In: Mindell, D. P. (ed.), Avian molecular evolution and systematics. Academic Press, pp. 159-171.

Silvertown, J. and McConway, K. J. 1997. Does "publication bias" lead to biased science? - Oikos 79: 167-168.

Stearns, S. C. 1992. The evolution of life histories. - Oxford Univ. Press.

Stenseth, N. C. et al. 2003. Studying climate effects on ecology through the use of climate indices: the North Atlantic Oscillation, El Niño Southern Oscillation and beyond. - Proc. R. Soc. B 270: 2087-2096.

Stenseth, N. C. et al. (eds) 2004. Marine ecosystems and climate variation: the North Atlantic - a comparative perspective. - Oxford Univ. Press.

Strauch, J. G. Jr 1985. The phylogeny of the Alcidae. - Auk 102: $520-539$.

Thomas, G. H. et al. 2004. Phylogeny of shorebirds, gulls, and alcids (Aves: Charadrii) from the cytochrome-b gene: parsimony, Bayesian inference, minimum evolution, and quartet puzzling. - Mol. Phylogen. Evol. 30: 516-526.

Thompson, P. M. and Ollason, J. C. 2001. Lagged effects of ocean climate change on fulmar population dynamics. - Nature 413: 417-420.

Download the appendix as file E5090 from

$<$ www.oikos.ekol.lu.se/appendix $>$.
Thompson, P. M. and Grosbois, V. 2002. Effects of climate variation on seabird population dynamics. - Dir. Sci. 1: 50 52.

Trenberth, K. E. 2001a. El Niño Southern Oscillation (ENSO). In: Steele, J. H. et al. (eds), Encyclopedia of ocean sciences. Academic Press, pp. 815-827.

Trenberth, K. E. 2001b. Climate variability and global warming. - Science 293: 48-49.

Viot, C. R. et al. 1993. Population genetics of southern seabirds. - Mar. Ornithol. 21: 1-25.

Votier, S. C. et al. 2005. Oil pollution and climate have wide-scale impacts on seabird demographics. - Ecol. Lett. 8: 1157-1164.

Walther, G.-R. et al. 2002. Ecological responses to recent climate change. - Nature 416: 389-395.

Wanless, S. et al. 1996. Modelling responses of herring gull and lesser black-backed gull populations to reduction of reproductive output: implications for control measures. - J. Appl. Ecol. 33: 1420-1432.

Weimerskirch, H. 2002. Seabird demography and its relationship with the marine environment. - In: Schreiber, E. A. and Burger, J. (eds), Biology of marine birds. CRC, pp. 115-135. Wooller, R. D. et al. 1992. Long-term population studies of seabirds. - Trends Ecol. Evol. 7: 111-114. 